\title{
Genomic and pedigree estimation of inbreeding depression for semen traits in the Basco-Béarnaise dairy sheep breed
}

\author{
S. Antonios, ${ }^{1}$ S. T. Rodríguez-Ramilo, ${ }^{1} \odot$ I. Aguilar, ${ }^{2} \odot$ J. M. Astruc,${ }^{3}$ A. Legarra,,${ }^{1} \odot$ and Z. G. Vitezica ${ }^{1 *} \odot$ \\ ${ }^{1}$ GenPhySE, INPT, INRAE, ENVT, F-31326, Castanet Tolosan, France \\ ${ }^{2}$ Instituto Nacional de Investigación Agropecuaria (INIA), 11100, Montevideo, Uruguay \\ ${ }^{3}$ Institut de l'Elevage, 149 rue de Bercy, F-75595 Paris, France
}

\section{ABSTRACT}

Inbreeding depression is associated with a decrease in performance and fitness of the animals. The goal of this study was to evaluate pedigree-based and genomic methods to estimate the level of inbreeding and inbreeding depression for 3 semen traits (volume, concentration, and motility score) in the Basco-Béarnaise sheep breed. Data comprised 16,196 (or 15,071) phenotypic records from 620 rams (of which 533 rams had genotypes of $36,464 \mathrm{SNPs}$ ). The pedigree included 8,266 animals, composed of the 620 rams and their ancestors. The number of equivalent complete generations for the 620 rams was 7.04. Inbreeding coefficients were estimated using genomic and pedigree-based information. Genomic inbreeding coefficients were estimated from individual SNP and using segments of homozygous SNP (runs of homozygosity, ROH). Short ROH are of old origin, whereas long $\mathrm{ROH}$ are due to recent inbreeding. Considering that the equivalent number of generations in Basco-Béarnaise was 6, inbreeding coefficients for $\mathrm{ROH}$ with a length $>4 \mathrm{Mb}$ refer to all (recent + old) inbreeding, those with a length $>17 \mathrm{Mb}$ correspond to recent inbreeding, and the difference between them indicates old inbreeding. Pedigree-based inbreeding coefficients were also estimated classically, or accounting for nonzero relationships for unknown parents, or including metafounder relationships (estimated using markers) to account for missing pedigree information. Finally, inbreeding coefficients combining genotyped and nongenotyped animal information were computed from matrix $\mathbf{H}$ of the single-step approach, also including metafounders. Inbreeding depression was estimated differently depending on the approach used to compute inbreeding coefficients. These 8 estimators of inbreeding coefficients were included as covariates in different animal models. No inbreeding depression was detected for sperm volume or sperm concentration.

Received April 21, 2020.

Accepted October 5, 2020.

*Corresponding author: zulma.vitezica@inrae.fr
Inbreeding depression was significant for the motility of spermatozoa. The effect of old and recent inbreeding on motility was null and negative, respectively, demonstrating the existence of purging by selection of deleterious recessive alleles affecting motility. A 10\% increase in inbreeding would result in a reduction in mean motility ranging between 0.09 and 0.22 points in the score (from 0 to 5). Motility is unfavorably affected by increasing recent inbreeding but the impact is very small. Runs of homozygosity and metafounders allow us to accurately estimate inbreeding depression and detect recent inbreeding.

Key words: inbreeding depression, runs of homozygosity $(\mathrm{ROH})$, metafounder, semen trait, BascoBéarnaise sheep

\section{INTRODUCTION}

Inbreeding depression is the reduction, due to inbreeding, of the mean phenotypic value shown by traits connected with fitness. Many important traits in dairy cattle, such as yield, fertility (González-Recio et al., 2007; Pryce et al., 2014), and udder health (Doekes et al., 2019), as well as semen quality traits (Ferenčaković et al., 2017) show inbreeding depression. Two alternative hypotheses may explain inbreeding depression: the partial dominance and the overdominance hypotheses in the absence of epistasis (Charlesworth and Willis, 2009). The "dominance" hypothesis argues that inbreeding depression is caused by the presence of recessive alleles in populations. These alleles, present at low frequencies in populations, can contribute to inbreeding depression because homozygotes are rare, except after inbreeding. Alternatively, the "overdominance" hypothesis refers to the loss of advantage from alleles with heterozygous superiority due to the increase of homozygosity. Partial dominance seems to account for a large proportion of the inbreeding depression (Leroy, 2014; Curik et al., 2017; Howard et al., 2017).

Inbreeding depression can be estimated from the regression of the phenotype on inbreeding coefficients. Classically, the inbreeding coefficient is defined as 
the probability that both alleles at any locus within an individual are identical by descent (IBD), and has been computed from pedigree information (Lynch and Walsh, 1998). However, pedigree information is often incomplete to some extent; it may contain errors and inbreeding may therefore be underestimated. Different methods are available to compute inbreeding coefficients for populations with missing pedigrees (VanRaden, 1992; Aguilar and Misztal, 2008). Also, computation of the inbreeding coefficient from pedigree assumes an infinitesimal model with unrelated loci. The availability of SNPs allows us to estimate genomic inbreeding coefficients from individual SNP or from segments of homozygous SNP (runs of homozygosity, ROH). These genomic inbreeding coefficients are expected to be more accurate because they reflect that inheritance is passed on in chromosomes (e.g., Baes et al., 2019; Maltecca et al., 2020). Genomic inbreeding coefficient estimates obtained from individual SNP refer to the proportion of homozygous genotypes (Silió et al., 2013) and do not use information from contiguous markers. Genomic inbreeding coefficient estimates based on $\mathrm{ROH}$ provide a better measure of inbreeding because they contemplate the joint occurrence of inbreeding in neighboring markers, and the length of $\mathrm{ROH}$ can give insight into the age of inbreeding, allowing us to distinguish between recent and old inbreeding (Curik et al., 2017; Doekes et al., 2019). Old inbreeding is typically less relevant because it is expected to be purged from deleterious load, whereas recent inbreeding is not.

Two obstacles to compute inbreeding in dairy sheep are the lack of pedigree recording and the lack of genotyping. Pedigree is sometimes missing because the sire is (usually) not recorded except for AI offspring. VanRaden (1992) proposed a method to estimate inbreeding coefficients compensating for missing pedigrees. Essentially the method consists of assigning relationships to pools of missing parents. Legarra et al. (2015) proposed a similar idea, called metafounders, where these relationships were obtained based on markers of descendants of these pools.

Genomic methods (e.g., ROH) are powerful but require that all animals have been genotyped. This is rarely the case in sheep populations. Single-step methods (Aguilar et al., 2010; Christensen and Lund, 2010), that project genomic relationships to all nongenotyped members of the pedigree, alleviate such problems and permit us to estimate single SNP-based genomic inbreeding coefficients (but not $\mathrm{ROH}$ ) for all animals (genotyped and nongenotyped). Recently, different methods to efficiently compute inbreeding coefficients were proposed (Legarra et al., 2020) and they include the use of metafounders (Legarra et al., 2015; Garcia-
Baccino et al., 2017) as an option for modeling missing pedigrees.

In dairy sheep, AI with fresh semen is used for reproductive and genetic purposes. Success of AI depends on male fertility and sperm quality, among other factors. In dairy cattle, several studies concluded that sperm quality is susceptible to inbreeding depression (e.g., Maximini et al., 2011; Ferenčaković et al., 2017). However, to date, the effect of inbreeding on semen traits has not been quantified in dairy sheep data. Artificial insemination rams play a major role in dairy sheep selection schemes, and monitoring of inbreeding depression on semen traits is of interest.

The goal of this study is to evaluate pedigree-based and genomic methods to estimate the level of inbreeding and inbreeding depression for semen traits (sperm volume, concentration, and motility) in Basco-Béarnaise rams.

\section{MATERIALS AND METHODS}

Data for this study were extracted from the French National dairy sheep database for the Basco-Béarnaise breed. Animal care and use committee approval was not necessary for this study because the data were obtained from an existing database.

\section{Phenotypic and Genomic Data}

Due to the use of fresh semen, a large population of rams is held at the AI center (Centre Départemental de l'Élevage Ovin), in Ordiarp, Pyrénées Atlantiques, France). Semen production and quality data is routinely collected; we use data for rams born between 1997 and 2015. Sperm volume $(\mathrm{mL})$ was evaluated directly by reading the collection tube. Sperm concentration $\left(\times 10^{6}\right.$ spermatozoa $/ \mathrm{mL}$ ) was determined by spectrophotometer. Motility score was evaluated by a technician on a scale from 0 (no motion) to 5 (numerous rapid and vigorous waves) under the microscope. Sperm quality data were assessed immediately after collection. Diluted semen was packaged in straws and stored at $15^{\circ} \mathrm{C}$ until cervical insemination (within $6 \mathrm{~h}$ following collection). Data comprised 16,196 phenotypic records from 620 rams born between 1997 and 2015. Summaries of the whole data for different semen traits are presented in Table 1.

Of the 620 rams with records, genotyped animals were a subset of 533 rams. These rams were genotyped using the OvineSNP50 BeadChip (Illumina Inc., San Diego, CA). The distribution of rams and status (genotyped or not) across year of birth is shown in Figure 1. After quality control using preGSf90 (Aguilar et al., 2014), 
36,464 autosomal SNP were retained for analyses and used to build genomic relationship matrices. In quality control, SNPs with a call rate $<0.98$, a minor allele frequency $<0.05$, and high deviation from Hardy-Weinberg equilibrium (absolute difference between expected and observed heterozygotes $>0.15$ ) were removed. Animals with a call rate $<0.98$ were discarded.

Pedigrees were extracted from the national database. There were 8,266 animals in the pedigree, composed of the $620 \mathrm{rams}$ and their ancestors. To assess pedigree completeness, the number of equivalent complete generations was computed using PEDIG (Boichard, 2002) and it was equal to 4.95 for all animals and to 7.04 for the 620 rams in the analyses. In the complete pedigree, 14 and $10 \%$ of the animals had 1 or 2 unknown parents, respectively. However, animals missing one or both parents are females (e.g., they could be great-granddams of the 620 rams), and pedigree completeness of rams was very high: as these are elite animals, all AI rams have at least 2 parents and 4 grandparents known.

\section{Genomic Inbreeding Estimation}

Inbreeding coefficient based on individual SNP $\left(F_{S N P}\right)$ was defined as the proportion of homozygous SNP in each animal (Silió et al., 2013). Thus, for animal $i$ $\left(F_{S N P_{i}}\right)$, it was calculated for the whole genome as follows:

$$
F_{S N P_{i}}=\frac{N_{A A}+N_{a a}}{N_{A A}+N_{A a}+N_{a a}}
$$

where $N_{A A}, N_{A a}$, and $N_{a a}$ refer to the number of SNP classified as $A A, A a$, and $a a$, respectively.

The inbreeding coefficient based on $\mathrm{ROH}\left(F_{R O H}\right)$ is the proportion of the genome that is in $\mathrm{ROH}$. For animal $i, F_{R O H_{i}}$ was calculated as

$$
F_{\mathrm{ROH}_{i}}=\frac{\sum_{k=1}^{n_{\mathrm{ROH}}} l_{\mathrm{ROH}_{i k}}}{l_{g}},
$$

where $n_{R_{O H}}$ represents the total number of $\mathrm{ROH}$ in animal $i, l_{R O H_{i k}}$ is the length of the $k$ th $\mathrm{ROH}$ in animal $i$ in base pairs, and $l_{g}$ is the length of the genome in base pairs. The $\mathrm{ROH}$ were obtained using a self-made Fortran program used previously in Rodríguez-Ramilo et al. $(2015,2019)$.

Several criteria exist for identifying a $\mathrm{ROH}$, which involve the homozygous or heterozygous state of the SNP and its map position. The criteria and values as-
Table 1. Mean, standard deviation, and range of the evaluated semen traits

\begin{tabular}{lccc}
\hline Trait & Mean & SD & Range \\
\hline Volume $(\mathrm{mL})$ & 1.41 & 0.63 & $0.20-4.80$ \\
Concentration $\left(\times 10^{6}\right.$ spermatozoa $\left./ \mathrm{mL}\right)$ & 3.23 & 0.64 & $1.60-5.50$ \\
Motility (score 0 to 5) & 4.61 & 0.54 & $0.00-4.98$ \\
\hline
\end{tabular}

sessed in this study were as follows: (1) the minimum length that constituted a $\mathrm{ROH}$ was $4 \mathrm{Mb}$; (2) the minimum number of SNP was 30; (3) the minimum density was $1 \mathrm{SNP} / 100 \mathrm{~kb}$; (4) the maximum distance allowed between 2 consecutive homozygous SNP was $1 \mathrm{Mb}$; (5) a maximum of 2 missing genotypes was permitted; and (6) only one heterozygous genotype was allowed. Recently, Rodríguez-Ramilo et al. (2019) showed that this set of values is appropriate for the Basco-Béarnaise breed.

Runs of homozygosity due to recent inbreeding are expected to be longer than those due to old inbreeding (repeated meiosis splits homozygous segments; McQuillan et al., 2008). To determine the number of generations from a common ancestor $(g c A)$ and, consequently, to differentiate recent from old inbreeding, the following formula was used (Curik et al., 2014): $E\left(L_{I B D-H} \mid g c A\right)=100 /(2 g c A)$, where $E\left(L_{I B D-H} \mid g c A\right)$ is the expected length of an IBD haplotype. This means that $\mathrm{ROH}$ with a minimum length of $4 \mathrm{Mb}$ come from a common ancestor occurring 12.5 generations ago on

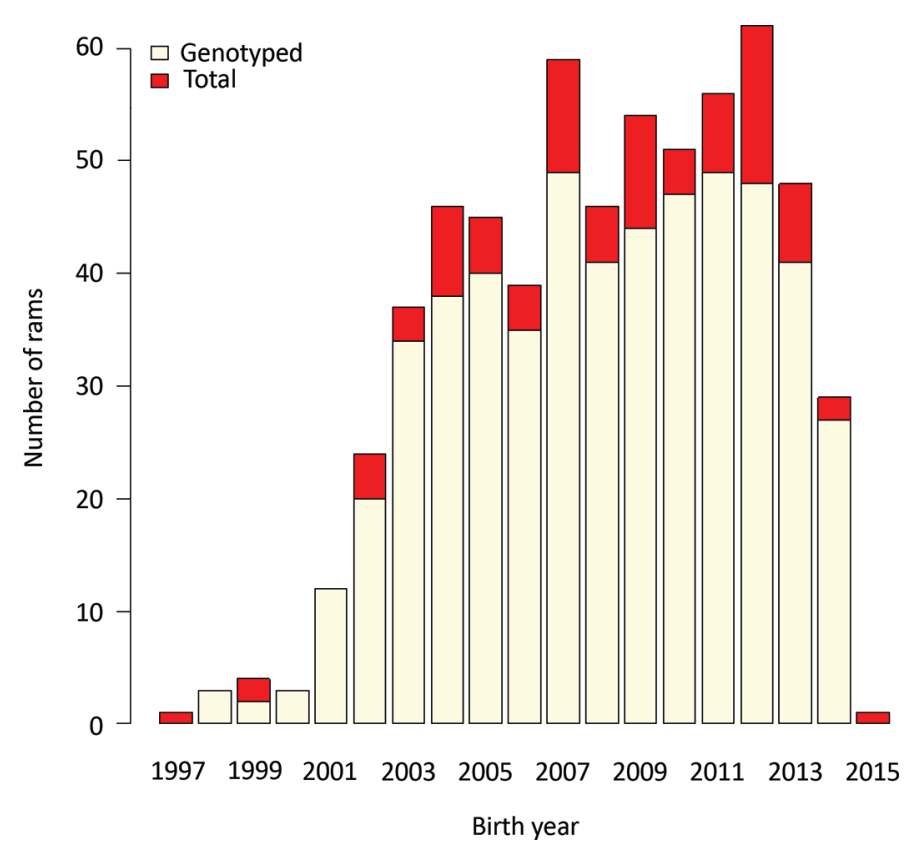

Figure 1. Distribution of total and genotyped rams in the data set across birth years. 
average. Accordingly, $\mathrm{ROH}$ with a minimum length of $17 \mathrm{Mb}$ come from a common ancestor occurring 3 generations ago on average, because $\mathrm{ROH}$ of a specific length comprise mixtures of several ancestral generations (Doekes et al., 2019). In total, 6,334 ROH were detected, considering all individuals and autosomes. Figure 2 shows the distribution of the number of $\mathrm{ROH}$ detected for each $\mathrm{ROH}$ category. The frequency of $\mathrm{ROH}$ between 4 and $17 \mathrm{Mb}$ was $0.88(5,565 \mathrm{ROH})$ and 0.12 for $\mathrm{ROH}>17 \mathrm{Mb}(770 \mathrm{ROH})$. In relation to the expected age of inbreeding, $F_{R O H>4 M b}$ refers to all inbreeding, $F_{R O H>17 M b}$ to recent inbreeding, and $F_{R O H>4-17 M b}=$ $F_{R O H>4 M b}-F_{R O H>17 M b}$ refers to old inbreeding. In the next sections, $F_{R O H>4 M b}, F_{R O H>4-17 M b}$, and $F_{R O H>17 M b}$ are called $F_{R O H_{\text {Total }}}, \quad F_{R O H_{O l d}}$, and $F_{R O H_{\text {Recent }}}$, respectively. Inbreeding coefficient estimates based on $\mathrm{ROH}$ were calculated for the whole genome.

\section{Pedigree Inbreeding Estimation}

Pedigree-based inbreeding coefficients were estimated using 4 methods. The first method $\left(F_{P E D}\right)$ used traditional pedigree-based inbreeding. The second method $\left(F_{P E D_{\text {nonzero }}}\right)$ used pedigree-based inbreeding but accounting for nonzero relationships for unknown parents (VanRaden, 1992; Aguilar and Misztal, 2008). In this approach, animals with missing parents were assumed to have inbreeding coefficients equal to the mean of the inbreeding coefficients for animals with known parents born during the same year. The third method used the metafounder relationships in pedigree-based inbreeding $\left(F_{P E D_{M F}}\right)$; that is, it compensated for missing pedigrees

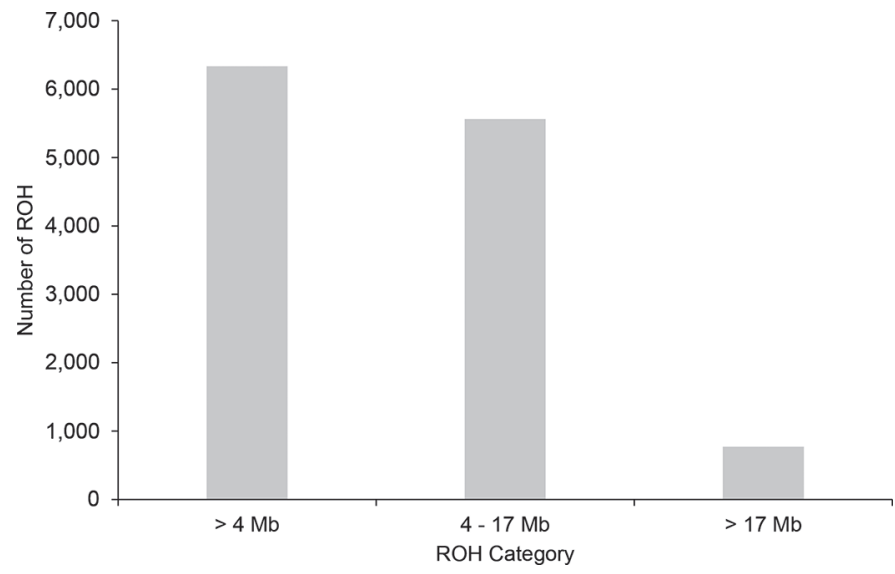

Figure 2. Distribution of the number of runs of homozygosity $(\mathrm{ROH})$ detected for each $\mathrm{ROH}$ category: with a minimum length of $4 \mathrm{Mb}, \mathrm{ROH}$ between 4 and $17 \mathrm{Mb}$, and $\mathrm{ROH}$ with a minimum length of $17 \mathrm{Mb}$ by assigning nonzero relationships to metafounders. Metafounders are pseudo-animals that represent relationships across and within base populations. For instance, unknown parents of an animal born in 2000 are likely offspring of animals born in 1996, but this relationship is lost if metafounders are not used. We used 5 metafounders, as described below. The fourth method calculates inbreeding from a combined relationship matrix $(\mathbf{H})$ using pedigree and genotypes with metafounder relationships $\left(F_{H_{M F}}\right)$. The diagonal element of matrix $\mathbf{H}-1$ gives an estimate of the inbreeding coefficient. For genotyped animals, it can be shown that $2 F_{S N P}=1+F_{H_{M F}}$ (Garcia-Baccino et al., 2017).

In this study, 5 metafounders were defined as a function of birth year of animals with unknown parent: 1974-1980, 1980-1988, 1988-1994, 1994-2000, and $>2000$. Ancestral relationships or relatedness for base animals (matrix $\boldsymbol{\Gamma}$ ) were estimated from pedigree and genotypes of the 533 genotyped rams using generalized least squares (Garcia-Baccino et al., 2017).

\section{Evaluation Models}

Phenotypes were analyzed using separate single-trait mixed models (multiple-trait analyses gave similar results). The combined effect of year-season of collection, daily variation (a.m./p.m.), age at collection (years), and the interval from previous collection (days, from 1 to 8 ) were included as fixed effects. The model also included a random permanent effect for each ram. For a single trait, the linear model can be written as

$$
\mathbf{y}=\mathbf{X} \boldsymbol{\beta}+\mathbf{F} b+\mathbf{Z}_{\mathrm{u}} \mathbf{u}+\mathbf{Z}_{\mathrm{pe}} \mathbf{p e}+\mathbf{e},
$$

where $\mathbf{y}$ is the vector of phenotypic records (volume, concentration, and motility), $\boldsymbol{\beta}$ is the vector of fixed effects, $\mathbf{u}$ is the vector of additive genetic effects, pe is the vector of permanent environmental effects $\left(\operatorname{Var}(\mathbf{p e})=\mathbf{I} \sigma_{p e}^{2}\right), \mathbf{e}$ is a residual vector $\left(\operatorname{Var}(\mathbf{e})=\mathbf{I} \sigma_{e}^{2}\right)$, and $\mathbf{X}$ and $\mathbf{Z}$ are design matrices relating records to fixed and random effects, respectively; $\sigma_{p e}^{2}$ and $\sigma_{e}^{2}$ are permanent and residual variances, respectively. The effect of technician was not included because the same person assessed the motility score during all semen collection periods in our data.

The term $\mathbf{F} b$ models inbreeding depression, where $b$ is the inbreeding depression parameter per unit of inbreeding, and the covariate $\mathbf{F}$ is the vector of inbreeding coefficients. Eight different inbreeding coefficients were considered, 4 genomic 
$\left(F_{S N P}, F_{R O H_{T o t a l}}, F_{R O H_{O l d}}\right.$, and $\left.F_{R O H_{\text {Recent }}}\right)$ and 4 pedigree-based $\left(F_{P E D}, F_{P E D_{\text {nonzero }}}, F_{P E D_{M F}}\right.$, and $\left.F_{H_{M F}}\right)$. Accordingly, the use of these 8 inbreeding coefficients defined 7 models: $\mathrm{SNP}, \mathrm{ROH}_{\text {Total }}, \mathrm{ROH}_{\text {Old }}+\mathrm{ROH}_{\text {Recent }}$, $\mathrm{PED}, \mathrm{PED}_{\text {nonzero }}, \mathrm{PED}_{\mathrm{MF}}$, and $\mathrm{H}_{\mathrm{MF}}$, respectively. The $\mathrm{ROH}_{\mathrm{Old}}+\mathrm{ROH}_{\text {Recent }}$ model fitted $F_{\text {ROH }}$ ald and $F_{\text {ROH }}$ Recent simultaneously. In addition, the models differed in the number of records used and in the relationship matrices used for $\operatorname{Var}(\mathbf{u})$ in the linear model, and this is detailed next.

The first 3 (genomic) models (SNP, $\mathrm{ROH}_{\text {Total }}$, $\left.\mathrm{ROH}_{\mathrm{Old}}+\mathrm{ROH}_{\text {Recent }}\right)$ included only 533 genotyped rams with 15,071 records, because the other rams did not have genotypes. In this case, $\operatorname{Var}(\mathbf{u})=\mathbf{G} \sigma_{u}^{2}$, where $\mathbf{G}$ is VanRaden (2008) genomic relationship matrix, $\sigma_{u}^{2}$ is the additive genetic variance, and a genomic $(\mathrm{G}) \mathrm{BLUP}$ was used.

The other 4 models (PED, $\mathrm{PED}_{\text {nonzero }}, \mathrm{PED}_{\mathrm{MF}}$, and $\mathrm{H}_{\mathrm{MF}}$ ) included the 16,196 records from the 620 rams. In the models $\mathrm{PED}$ and $\mathrm{PED}_{\text {nonzero, }} \operatorname{Var}(\mathbf{u})=\mathbf{A} \sigma_{u}^{2}$, the classical numerator relationship matrix. In the $\mathrm{PED}_{\mathrm{MF}}$ model, $\operatorname{Var}(\mathbf{u})=\mathbf{A}^{\Gamma} \sigma_{u}^{2}$, a pedigree-based relationship matrix but including metafounders. The last model, $\mathrm{H}_{\mathrm{MF}}$, was single-step GBLUP with metafounder relationships $\left(\operatorname{Var}(\mathbf{u})=\mathbf{H}^{\Gamma} \sigma_{u}^{2}\right)$ (Legarra et al., 2015).

Programs of the BLUPF90 family (Misztal et al., 2002) were used for the analyses and are available at http://nce.ads.uga.edu/wiki/doku.php.

\section{RESULTS AND DISCUSSION}

Several aspects affect the identification of $\mathrm{ROH}$ and the inference of age of inbreeding that is done based on them. The number and length of the detected $\mathrm{ROH}$ is sensitive to genome assembly, the thresholds imposed during the filtering of the genotypic data, and the parameters used to define a ROH (Howrigan et al., 2011). Therefore, ROH-based inbreeding coefficients are affected by the density of the SNP chip, the frequency of genotyping errors (Ferenčaković et al., 2013), and the number of heterozygotes allowed (Mastrangelo et al., 2016). Additionally, the location, frequency, and size of $\mathrm{ROH}$ can be influenced by recombination and mutation rates. In general, a uniform recombination rate is assumed but it varies across the genome (Gibson et al., 2006). In this study, the definition of $\mathrm{ROH}$ was rulebased and somewhat arbitrary, although several definitions were previously studied in Rodríguez-Ramilo et al. (2019) and this one retained because it seemed empirically adequate. Alternatively, a Hidden Markov model approach may be used to identify homozygous segments and to infer the age of inbreeding (Druet and Gautier, 2017).

Mean inbreeding coefficients across individuals for each method are shown in Table 2 and Figure 3. The mean $F_{S N P}, F_{R O H_{T o t a l}}$, and $F_{P E D}$ were $0.61,0.05$ and 0.04 , respectively.

Our inbreeding coefficient estimates agreed with values obtained in other sheep breeds: Manech Tête Rousse $\left(F_{S N P}=0.62, F_{R O H}=0.04\right.$, and $\left.F_{P E D}=0.02\right)$ and Lacaune $\left(F_{S N P}=0.62, F_{R O H}=0.04\right.$, and $F_{P E D}=$

Table 2. Mean inbreeding, standard deviations, and range of the evaluated coefficients

\begin{tabular}{lllcc}
\hline Inbreeding coefficient & Method $^{1}$ & Mean & SD & Range \\
\hline $\begin{array}{llll}\text { Marker-based } \\
(\mathrm{n}=533)^{2}\end{array}$ & $F_{S N P}$ & 0.6111 & 0.0099 & $0.5864-0.6519$ \\
& $F_{R O H_{\text {Total }}}$ & 0.0468 & 0.0235 & $0.0020-0.1444$ \\
& $F_{\text {ROH }}$ & 0.0337 & 0.0160 & $0.0020-0.0895$ \\
& $F_{\text {ROH }}$ & 0.0132 & 0.0144 & $0.0000-0.0884$ \\
$F_{\text {Recent }}$ & 0.0388 & 0.0174 & $0.0000-0.1031$ \\
$(\mathrm{n}=533)^{2}$ & $F_{P E D}$ & 0.0432 & 0.0162 & $0.0031-0.1066$ \\
& $F_{P E D_{\text {nonzero }}}$ & 0.2287 & 0.0155 & $0.1862-0.2783$ \\
& $F_{P E D_{M F}}$ & 0.2226 & 0.0193 & $0.1747-0.3017$ \\
\hline
\end{tabular}

${ }^{1}$ Inbreeding coefficients: $F_{S N P}=$ based on the proportion of homozygous SNP, $F_{R O H_{T o t a l}}=$ based on runs of homozygosity $(\mathrm{ROH})$ with a minimum length of $4 \mathrm{Mb}, F_{R O H_{\text {Old }}}=$ based on ROH between 4 and $17 \mathrm{Mb}$, $F_{R O H_{\text {Recent }}}=$ based on $\mathrm{ROH}$ with a minimum length of $17 \mathrm{Mb}, F_{P E D}=$ pedigree-based inbreeding, $F_{P E D_{\text {nonzero }}}$ $=$ pedigree-based inbreeding but accounting for nonzero relationships for unknown parents, $F_{P E D_{M F}}=$ pedigree-based inbreeding including metafounder relationships, and $F_{H_{M F}}=$ inbreeding calculated from a combined relationship matrix using pedigree and genotypes with metafounder relationships, respectively.

${ }^{2}$ Number of rams. 
0.03; Rodríguez-Ramilo et al., 2019), Latxa Cara Rubia $\left(F_{S N P}=0.61, F_{R O H}=0.03\right.$, and $F_{P E D}=0.02$; GranadoTajada et al., 2020) and Churra $\left(F_{R O H}=0.04\right.$; Chitneedi et al., 2017). However, low inbreeding coefficients were estimated in Finnsheep population $\left(F_{S N P}=0.04\right)$ using pedigree and SNPs (Li et al., 2011). The authors suggested this was due to the small sample size (99 animals) and incompleteness of the pedigree ( $\mathrm{Li}$ et al., 2011)

Comparing marker-based methods, the mean $F_{S N P}$ (0.61) was greater than $F_{R O H_{\text {Total }}}(0.05)$. Note that individual SNP inbreeding is a combination of IBD and identical by state, whereas $F_{R O H}$ represents only the IBD fraction (Curik et al., 2014; Zhang et al., 2015; Peripolli et al., 2017). The highest values of inbreeding among $F_{R O H}$ averages correspond to $F_{R O H_{T o t a l}}$. This was expected because it includes all fragments having a length $>4 \mathrm{Mb}$ (Ferenčaković et al., 2017). As expected, $F_{R O H_{T o t a l}}$ was close to the pedigree-based inbreeding coefficients $F_{P E D}$ and $F_{P E D_{\text {nonzero }}}$. Among pedigree-based coefficients, higher values were obtained for the methods that included metafounder relationships, $F_{P E D_{M F}}$ and $F_{H_{M F}}$. Inbreeding increases when considering metafounders (0.03 vs. 0.22; Legarra et al., 2015). However, inbreeding depression estimates are not affected, because adding a constant to a covariate does not change the regression. The inbreeding coefficients based on the pedigree data, $F_{P E D}$, were plotted against in-

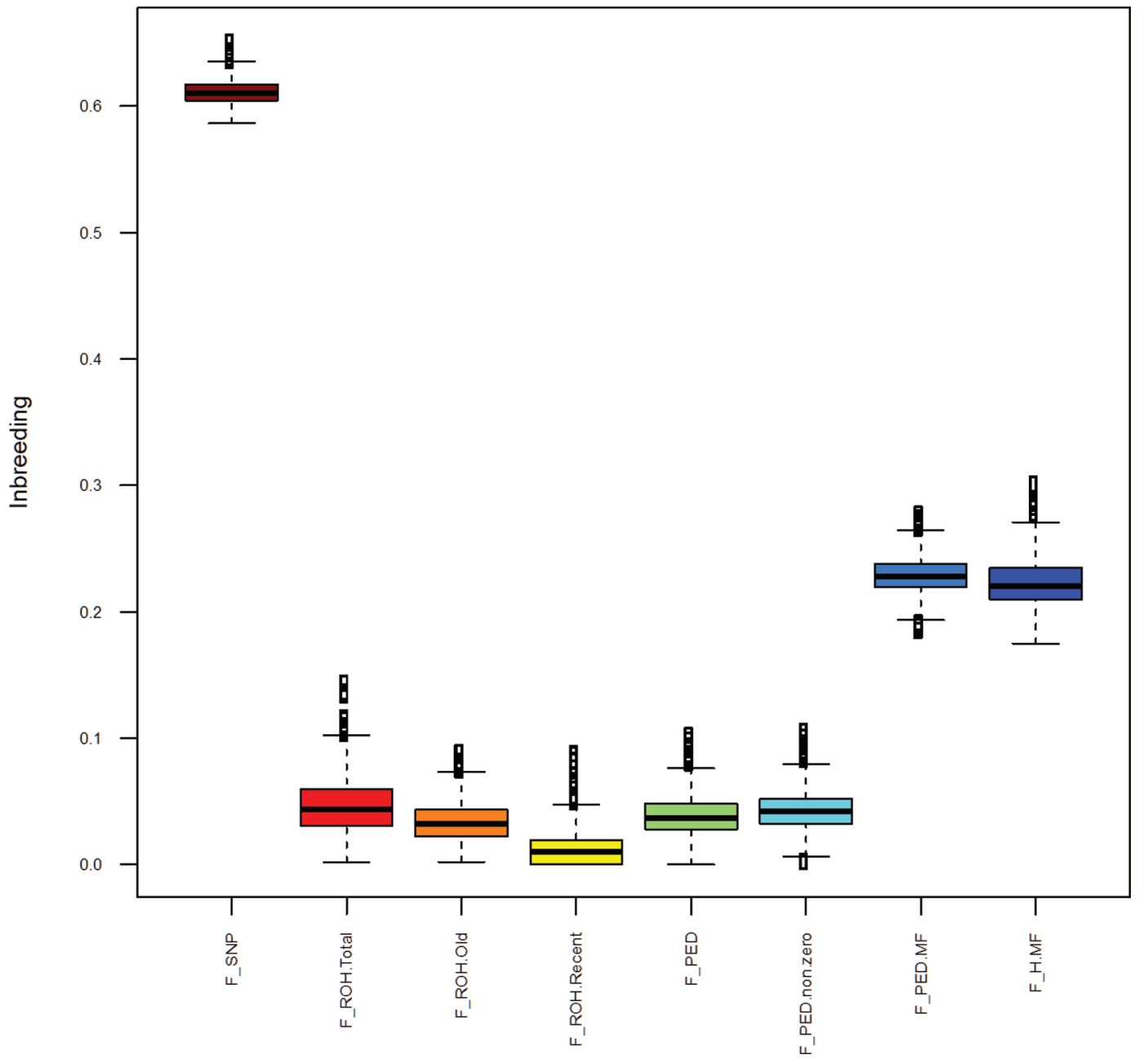

Figure 3. Estimations of inbreeding coefficients under genomic (F_SNP, F_ROH.Total, F_ROH.Old, and F_ROH.Recent) and pedigreebased (F_PED, F_PED.nonzero, F_PED.MF, and F_H.MF) methods. F_SNP = based on the proportion of homozygous SNP, F_ROH.Total = based on runs of homozygosity $(\mathrm{ROH})$ with a minimum length of $4 \mathrm{Mb}, \mathrm{F} \_\mathrm{ROH}$.Old = based on ROH between 4 and $17 \mathrm{Mb}, \mathrm{F} \_\mathrm{ROH}$.Recent = based on ROH with a minimum length of $17 \mathrm{Mb}, \mathrm{F} \_$PED = pedigree-based inbreeding, F_PED.nonzero = pedigree-based inbreeding but accounting for nonzero relationships for unknown parents, F_PED.MF = pedigree-based inbreeding with metafounder relationships, and F_H. $\mathrm{MF}$ = inbreeding calculated from a combined relationship matrix using pedigree and genotypes with metafounder relationships, respectively. 
breeding coefficients based on the genomic data, $F_{S N P}$ (see Supplemental Figure S1; https://doi.org/10.3168/ jds.2020-18761), and followed the expected relationship. All methods had similar variation in the estimates (Figure 3).

The correlations between the inbreeding coefficients for the 533 genotyped animals are shown in Figure 4. As expected, a high correlation was obtained between $F_{S N P}$ and $F_{R O H_{\text {Total }}}(0.86)$, because short ROH contain small fragments of continuous SNP. The correlation varied from 0.91 to 0.97 between pedigree-based inbreeding coefficients: $F_{P E D}, F_{P E D_{\text {nonzero }}}$, and $F_{P E D_{M F}}$. The highest correlation was between $F_{S N P}$ and $F_{H_{M F}}$ (1.00) because the corresponding block of $\mathbf{H}^{\Gamma}$ is proportional to an identical-by-state relationship $\mathbf{G}$ matrix (Garcia-Baccino et al., 2017). Pedigree-based inbreeding $\left(F_{P E D}\right)$ was moderately correlated with $F_{S N P}(0.59)$ and $F_{R O H_{T o t a l}}(0.60)$. A lower correlation was found

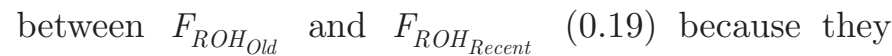
reflect different ages of inbreeding. In recent inbreeding, recombination and mutation have not yet fragmented the homozygous segments. Ignoring $F_{S N P}$, in-

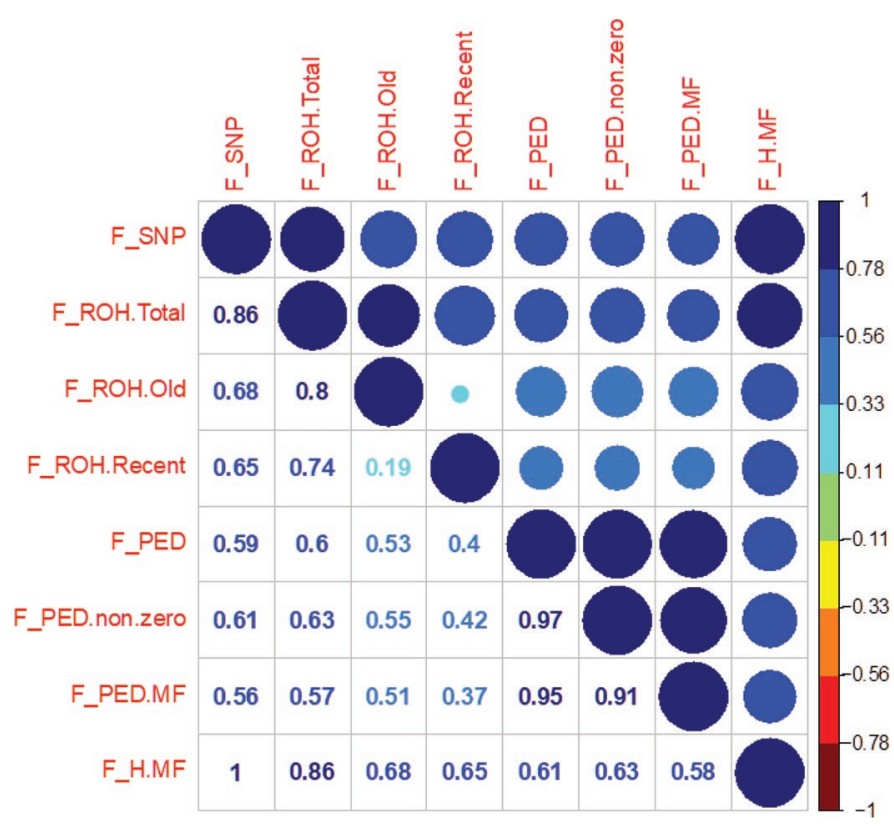

Figure 4. Correlations between different inbreeding coefficients: F_SNP = based on the proportion of homozygous SNP, F_ROH.Total = based on runs of homozygosity $(\mathrm{ROH})$ with a minimum length of $4 \mathrm{Mb}, \mathrm{F} \_$ROH.Old $=$based on ROH between 4 and $17 \mathrm{Mb}, \mathrm{F} \_$ROH. Recent $=$ based on ROH with a minimum length of $17 \mathrm{Mb}, \mathrm{F} \_\mathrm{PED}=$ pedigree-based inbreeding, F_PED.nonzero = pedigree-based inbreeding but accounting for nonzero relationships for unknown parents, $\mathrm{F}_{-}$ PED.MF = pedigree-based inbreeding with metafounder relationships, and $\mathrm{F} \_$H.MF $=$inbreeding calculated from a combined relationship matrix using pedigree and genotypes with metafounder relationships, respectively. breeding coefficients obtained from the $\mathbf{H}$ matrix including metafounder relationships $\left(F_{H_{M F}}\right)$ were mainly correlated with $F_{R O H_{T o t a l}}(0.86)$ with, in second and third place, $F_{R O H_{O l d}}(0.68)$ and $F_{R O H_{\text {Recent }}}(0.65)$ inbreeding, respectively.

Estimates of inbreeding depression for the 3 evaluated traits are shown in Table 3. No inbreeding depression was detected for sperm volume or concentration. Inbreeding depression for motility was significantly different from zero $(P<0.05)$ in $\mathrm{SNP}, \mathrm{ROH}_{\text {Total }}$, $\mathrm{ROH}_{\text {Recent }}, \mathrm{PED}_{\mathrm{MF}}$, and $\mathrm{H}_{\mathrm{MF}}$ (Table 3). The reduction in mean motility score ranged between 0.9 and $2.2 \%$ for $100 \%$ inbreeding. This means that a $10 \%$ increase in inbreeding would result in a reduction of the motility mean of around 0.1 points on the scale (from 0 to 5 ) and a slight deterioration in semen quality. The rate of inbreeding in this breed is $1 \%$ per generation. Thus, our results would not have a sensible economic impact for breeders.

No inbreeding depression was detected for motility with $\mathrm{ROH}_{\text {Old }}$ (which refers to old inbreeding). Note that recent and old inbreeding were fitted simultaneously to provide more accurate estimates. Similar results (not shown) were obtained when long or short $\mathrm{ROH}$ were included separately. A purging effect of deleterious alleles in old generations could explain this result (Mc Parland

Table 3. Inbreeding depression and standard error (in parentheses) for semen traits using different models

\begin{tabular}{|c|c|c|c|}
\hline \multirow[b]{2}{*}{ Model $^{1}$} & \multicolumn{3}{|c|}{ Semen trait ${ }^{2}$} \\
\hline & Volume & Concentration & Motility \\
\hline SNP & $-0.901(1.419)$ & $-0.752(1.589)$ & $-2.230(0.954)^{*}$ \\
\hline $\mathrm{ROH}_{\text {Total }}$ & $-0.931(0.609)$ & $-0.247(0.684)$ & $-0.905(0.413)^{*}$ \\
\hline $\mathrm{ROH}_{\text {Old }}$ & $-1.064(0.933)$ & $0.860(1.032)$ & $-0.556(0.624)$ \\
\hline $\mathrm{ROH}_{\text {Bece }}$ & $-0.797(0.943)$ & $-1.072(1.064)$ & $-1.534(0.643)^{*}$ \\
\hline PED & $-0.096(0.880)$ & $1.104(0.978)$ & $-1.241(0.681)$ \\
\hline $\mathrm{PED}_{\text {nonzero }}$ & $-0.290(0.996)$ & 1.056 (1.108) & $-1.259(0.771)$ \\
\hline $\mathrm{PED}_{\mathrm{MF}}$ & $-0.979(1.006)$ & $1.617(1.103)$ & $-1.676(0.768)^{*}$ \\
\hline $\mathrm{H}_{\mathrm{MF}}$ & $-0.248(0.703)$ & $0.545(0.807)$ & $-1.115(0.557)^{*}$ \\
\hline
\end{tabular}

${ }^{1}$ The models SNP, $\mathrm{ROH}_{\text {Total }}, \mathrm{ROH}_{\text {Old }}, \mathrm{ROH}_{\text {Recent }}, \mathrm{PED}, \mathrm{PED}_{\text {nonzero, }}$, $\mathrm{PED}_{\mathrm{MF}}$, and $\mathrm{H}_{\mathrm{MF}}$, were defined according to the inbreeding coefficients used: $F_{S N P}=$ based on the proportion of homozygous SNP, $F_{R O H_{T o t a l}}$ $=$ based on runs of homozygosity $(\mathrm{ROH})$ with a minimum length of 4 $\mathrm{Mb}, F_{\text {ROH }_{\text {Old }}}=$ based on $\mathrm{ROH}$ between 4 and $17 \mathrm{Mb}, F_{\text {ROH }}$ Recent $=$ based on $\mathrm{ROH}$ with a minimum length of $17 \mathrm{Mb}, F_{P E D}=$ pedigreebased inbreeding, $F_{P E D_{\text {nonzero }}}=$ pedigree-based inbreeding but accounting for nonzero relationships for unknown parents, $F_{P E D_{M F}}=$ pedigree-based inbreeding including metafounder relationships, and $F_{H_{M F}}$ = inbreeding calculated from a combined relationship matrix using pedigree and genotypes with metafounder relationships, respectively. ${ }^{2}$ Values are expressed as the change in phenotypic mean per $100 \%$ increase in inbreeding.

$* P<0.05$. 
et al., 2009). This purging effect has been identified in plants and animals (Leroy, 2014). Purge occurs if selection for a specific trait is strong relative to drift, leading to elimination of the deleterious alleles. The difference between the old inbreeding depression and the new may be due to the fact that old deleterious alleles have been purged compared with new ones. To confirm the purge effect, recent and old inbreeding were analyzed based on pedigree using Kalinowski's inbreeding coefficients $\left(\boldsymbol{F}_{\boldsymbol{K} A L}\right.$; Doekes et al., 2019; 2020). However, the variance of $F_{K A L}$ was very small (0.000052) compared with the variance of $F_{P E D}(0.0003)$. Thus, including $F_{K A L}$ as a covariate in a mixed model has no power to detect inbreeding depression in this data set. Our results are in line with Hinrichs et al. (2007), where only recent inbreeding seems to cause an inbreeding depression effect due to purge. However, Doekes et al. (2019) recently showed that both long and short $\mathrm{ROH}$ contributed to inbreeding depression for yield, fertility, and udder traits in Dutch Holstein-Friesian dairy cattle.

Inbreeding had a detrimental effect only on motility. This finding may lead us to think that the estimated effect of inbreeding on motility is an artifact due to, for example, lack of variation in motility scores. However, the absence of variation in motility scores is due to the high quality of ejaculates produced by AI rams. Furthermore, even if the method is subjective, only one technician assessed motility score during the annual semen collection period, which ensures the quality of the data. Other evidence that motility scores are reliable is the strong relationship between mass sperm motility and fertility (lambing rate) shown in several sheep breeds, including Basco-Béarnaise (David et al., 2015). The consistency of results from this latter study across different breeds confirms that motility score is an appropriate test despite its apparent subjectivity. In the future, it would be interesting to use an objective measure of sperm motility, such as computer-assisted sperm analysis (CASA), to select ejaculates for insemination.

Several studies indicate that inbreeding depression reduces semen quality traits (Gage et al., 2006; Fitzpatrick and Evans, 2009; Maximini et al., 2011; Ferenčaković et al., 2017). As in this study, Maximini et al. (2011) showed that inbreeding depression reduced sperm motility of Fleckvieh bulls. Sperm quality seems to be susceptible to inbreeding depression due to the dependence of spermatogenesis on highly regulated developmental genes and to the appearance of deleterious alleles or loss in heterozygosity (Gage et al., 2006; Fitzpatrick and Evans, 2009). Recently, Dorado et al. (2017) indicated that high inbreeding had a moderate effect on semen quality with an increased level of nonprogressive spermatozoa despite its high activity. These studies were carried out in wild populations
(Gage et al., 2006; Fitzpatrick and Evans, 2009) or in cattle (Maximini et al., 2011; Ferenčaković et al., 2017; Dorado et al., 2017). We are not aware of other studies on the effect of inbreeding on semen quality in sheep.

In sheep, complete pedigrees are difficult to obtain because of the use of natural mating. Metafounders help with missing pedigree information, because ancestral relationships are invariable to depth and completeness of the pedigree. Missing parents were modeled as animals coming from base populations that might be related and inbred. Inclusion of metafounders in classical pedigree-based or single-step genetic evaluation methods $\left(\mathrm{PED}_{\mathrm{MF}}\right.$ and $\left.\mathrm{H}_{\mathrm{MF}}\right)$ allowed us to capture recent inbreeding that causes inbreeding depression in motility. Thus, suitable methods to estimate inbreeding and inbreeding depression in Basco-Béarnaise are (1) singlestep GBLUP with regression on inbreeding coefficient $F_{H_{M F}}$, obtained jointly for genotyped and nongenotyped individuals with metafounder relationships; or (2) GBLUP with joint regression on 2 inbreeding coefficients: $F_{R O H_{\text {Old }}}$ and $F_{R O H_{\text {Recent }}}$.

Motility was unfavorably affected by increasing inbreeding in the Basco-Béarnaise breed. Even if the small decline in semen quality does not imply a negative economic effect for breeders, this opens the question of inbreeding management. Today, inbreeding is managed through mating plans in the Basco-Béarnaise breed, and the rate of inbreeding is currently $1 \%$ per generation, which is low. Genomic selection has been applied in Basco-Béarnaise since 2015. We could expect an inbreeding rate higher than that with pedigree-based selection. Thus, inbreeding coefficients combining genotyped and nongenotyped animals could be incorporated in an optimum contribution selection strategy (Meuwissen, 1997). In addition, instead of global inbreeding, it would be interesting to identify individuals that differ in inbreeding loads (Casellas, 2018; Varona et al., 2019). Individuals with less inbreeding depression load may be selected to avoid inbreeding depression in future generations.

\section{CONCLUSIONS}

Runs of homozygosity allowed us to accurately estimate inbreeding depression and to detect "recent" inbreeding. However, the use of ROHs is restricted to genotyped animals. Inbreeding occurring in recent generations affects inbreeding depression. The use of metafounders is an interesting method to estimate inbreeding depression caused by recent inbreeding in incomplete pedigrees, including genotyped and nongenotyped animals. No inbreeding depression was detected for sperm volume or concentration. Motility 
of spermatozoa was unfavorably affected by increased inbreeding in the Basco-Béarnaise breed. However, the effect of old inbreeding on motility was null, perhaps showing the existence of purging of deleterious recessive alleles affecting motility. A $10 \%$ increase in inbreeding would result in reduction in the mean motility of 0.1 point in the 0 to 5 motility scale. Given the low increase of inbreeding, this small decline in semen quality does not imply a negative economic impact for breeders.

\section{ACKNOWLEDGMENTS}

The authors thank Valérie Loywyck (Institut de l'Élevage) who provided the data, and Francis Fidelle, head of AI center (Centre Départemental de l'Élevage Ovin), who took the measures. This study received funding from the European Union Horizon 2020 Research and Innovation programme under grant agreement No. 772787 - SMARTER, projects ARDI (grant agreement EFA 208/16) from POCTEFA funds, and GDivSelGen (INRA SelGen metaprogram). Project was partly supported by Toulouse Midi-Pyrénées bioinformatics platform. The authors have not stated any conflicts of interest.

\section{REFERENCES}

Aguilar, I., and I. Misztal. 2008. Recursive algorithm for inbreeding coefficients assuming nonzero inbreeding of unknown parents. J. Dairy Sci. 91:1669-1672. https://doi.org/10.3168/jds.2007-0575.

Aguilar, I., I. Misztal, D. L. Johnson, A. Legarra, S. Tsuruta, and T. J. Lawlor. 2010. Hot topic: A unified approach to utilize phenotypic, full pedigree, and genomic information for genetic evaluation of Holstein final score. J. Dairy Sci. 93:743-752. https://doi.org/10 $.3168 /$ jds.2009-2730.

Aguilar, I., I. Misztal, S. Tsuruta, A. Legarra, and H. Wang. 2014. PREGSF90 - POSTGSF90: Computational tools for the implementation of single-step genomic selection and genome-wide association with ungenotyped individuals in BLUPF90 programs. Page 680 in Proc. 10th World Congress on Genetics Applied to Livestock Production, Vancouver, Canada.

Baes, C. F., B. O. Makanjuola, F. Miglior, G. Marras, J. T. Howard, A. Fleming, and C. Maltecca. 2019. Symposium review: The genomic architecture of inbreeding: How homozygosity affects health and performance. J. Dairy Sci. 102:2807-2817. https://doi.org/10 $.3168 /$ jds.2018-15520.

Boichard, D. 2002. PEDIG: A Fortran package for pedigree analysis suited to large populations. Paper 28-13 in Proc. 7th World Congress on Genetics Applied to Livestock Production, Montpellier, France.

Casellas, J. 2018. On individual-specific prediction of hidden inbreeding depression load. J. Anim. Breed. Genet. 135:37-44. https://doi .org/10.1111/jbg.12308.

Charlesworth, D., and J. H. Willis. 2009. The genetics of inbreeding depression. Nat. Rev. Genet. 10:783-796. https://doi.org/10.1038/ nrg2664.

Chitneedi, P. K., J. J. Arranz, A. Suarez-Vega, E. García-Gámez, and B. Gutiérrez-Gil. 2017. Estimations of linkage disequilibrium, effective population size and $\mathrm{ROH}$-based inbreeding coefficients in Spanish Churra sheep using imputed high-density SNP genotypes. Anim. Genet. 48:436-446. https://doi.org/10.1111/age.12564.
Christensen, O. F., and M. S. Lund. 2010. Genomic prediction when some animals are not genotyped. Genet. Sel. Evol. 42:2. https:// doi.org/10.1186/1297-9686-42-2.

Curik, I., M. Ferenčaković, and J. Sölkner. 2014. Inbreeding and runs of homozygosity: A possible solution to an old problem. Livest. Sci. 166:26-34. https://doi.org/10.1016/j.livsci.2014.05.034.

Curik, I., M. Ferenčaković, and J. Sölkner. 2017. Genomic dissection of inbreeding depression: A gate to new opportunities. Rev. Bras. Zootec. 46:773-782. https://doi.org/10.1590/s1806 -92902017000900010.

David, I., P. Kohnke, G. Lagriffoul, O. Praud, F. Plouarboué, P. Degond, and X. Druart. 2015. Mass sperm motility is associated with fertility in sheep. Anim. Reprod. Sci. 161:75-81. https://doi.org/ 10.1016/j.anireprosci.2015.08.006.

Doekes, H. P., I. Curik, I. Nagy, J. Farkas, G. Kövér, and J. J. Windig. 2020. Revised calculation of Kalinowski's ancestral and new inbreeding coefficients. Diversity (Basel) 12:155. https://doi.org/ $10.3390 / \mathrm{d} 12040155$.

Doekes, H. P., R. F. Veerkamp, P. Bijma, G. de Jong, S. J. Hiemstra, and J. J. Windig. 2019. Inbreeding depression due to recent and ancient inbreeding in Dutch Holstein-Friesian dairy cattle. Genet. Sel. Evol. 51:54. https://doi.org/10.1186/s12711-019-0497-z.

Dorado, J., R. M. Cid, A. Molina, M. Hidalgo, J. Ariza, M. MorenoMillán, and S. Demyda-Peyrás. 2017. Effect of inbreeding depression on bull sperm quality and field fertility. Reprod. Fertil. Dev. 29:712-720. https://doi.org/10.1071/RD15324.

Druet, T., and M. Gautier. 2017. A model-based approach to characterize individual inbreeding at both global and local genomic scales. Mol. Ecol. 26:5820-5841. https://doi.org/10.1111/mec .14324 .

Ferenčaković, M., J. Sölkner, and I. Curik. 2013. Estimating autozygosity from high-throughput information: Effects of SNP density and genotyping errors. Genet. Sel. Evol. 45:42. https://doi.org/10 .1186/1297-9686-45-42.

Ferenčaković, M., J. Sölkner, M. Kapš, and I. Curik. 2017. Genomewide mapping and estimation of inbreeding depression of semen quality traits in a cattle population. J. Dairy Sci. 100:4721-4730. https://doi.org/10.3168/jds.2016-12164.

Fitzpatrick, J. L., and J. P. Evans. 2009. Reduced heterozygosity impairs sperm quality in endangered mammals. Biol. Lett. 5:320323. https://doi.org/10.1098/rsbl.2008.0734.

Gage, M. J. G., A. K. Surridge, J. L. Tomkins, E. Green, L. Wiskin, D. J. Bell, and G. M. Hewitt. 2006. Reduced heterozygosity depresses sperm quality in wild rabbits, Oryctolagus cuniculus. Curr. Biol. 16:612-617. https://doi.org/10.1016/j.cub.2006.02.059.

Garcia-Baccino, C. A., A. Legarra, O. F. Christensen, I. Misztal, I. Pocrnic, Z. G. Vitezica, and R. J. C. Cantet. 2017. Metafounders are related to Fst fixation indices and reduce bias in single-step genomic evaluations. Genet. Sel. Evol. 49:34. https://doi.org/10 $.1186 / \mathrm{s} 12711-017-0309-2$.

Gibson, J., N. E. Newton, and A. Collins. 2006. Extended tracts of homozygosity in outbred human populations. Hum. Mol. Genet. 15:789-795. https://doi.org/10.1093/hmg/ddi493.

González-Recio, O., E. L. De Maturana, and J. Gutiérrez. 2007. Inbreeding depression on female fertility and calving ease in Spanish dairy cattle. J. Dairy Sci. 90:5744-5752. https://doi.org/10.3168/ jds.2007-0203.

Granado-Tajada, I., S. T. Rodríguez-Ramilo, A. Legarra, and E. Ugarte. 2020. Inbreeding, effective population size, and coancestry in the Latxa dairy sheep breed. J. Dairy Sci. 103:5215-5226. https: //doi.org/10.3168/jds.2019-17743.

Hinrichs, D., T. H. Meuwissen, J. Ødegard, M. Holt, O. Vangen, and J. A. Woolliams. 2007. Analysis of inbreeding depression in the first litter size of mice in a long-term selection experiment with respect to the age of the inbreeding. Heredity 99:81-88. https://doi.org/ 10.1038/sj.hdy.6800968.

Howard, J. T., J. E. Pryce, C. Baes, and C. Maltecca. 2017. Invited review: Inbreeding in the genomics era: Inbreeding, inbreeding depression, and management of genomic variability. J. Dairy Sci. 100:6009-6024. https://doi.org/10.3168/jds.2017-12787. 
Howrigan, D. P., M. A. Simonson, and M. C. Keller. 2011. Detecting autozygosity through runs of homozygosity: A comparison of three autozygosity detection algorithms. BMC Genomics 12:460. https:/ /doi.org/10.1186/1471-2164-12-460.

Legarra, A., I. Aguilar, and J. J. Colleau. 2020. Methods to compute genomic inbreeding for ungenotyped individuals. J. Dairy Sci. 103:3363-3367. https://doi.org/10.3168/jds.2019-17750.

Legarra, A., O. F. Christensen, Z. G. Vitezica, I. Aguilar, and I. Misztal. 2015. Ancestral relationships using metafounders: Finite ancestral populations and across population relationships. Genetics 200:455-468. https://doi.org/10.1534/genetics.115.177014.

Leroy, G. 2014. Inbreeding depression in livestock species: Review and meta-analysis. Anim. Genet. 45:618-628. https://doi.org/10.1111/ age.12178.

Li, M. H., I. Strandén, T. Tiirikka, M. L. Sevón-Aimonen, and J. Kantanen. 2011. A comparison of approaches to estimate the inbreeding coefficient and pairwise relatedness using genomic and pedigree data in a sheep population. PLoS One 6:e26256. https:// doi.org/10.1371/journal.pone.0026256.

Lynch, M., and B. Walsh. 1998. Genetics and Analysis of Quantitative Traits. Sinauer, Sunderland, MA.

Maltecca, C., F. Tiezzi, J. B. Cole, and C. Baes. 2020. Symposium review: Exploiting homozygosity in the era of genomics-Selection, inbreeding, and mating programs. J. Dairy Sci. 103:5302-5313. https://doi.org/10.3168/jds.2019-17846.

Mastrangelo, S., M. Tolone, R. D. Di Gerlando, L. Fontanesi, M. T. Sardina, and B. Portolano. 2016. Genomic inbreeding estimation in small populations: Evaluation of runs of homozygosity in three local dairy cattle breeds. Animal 10:746-754. https://doi.org/10 $.1017 /$ S1751731115002943.

Maximini, L., B. Fuerst-Waltl, B. Gredler, and R. Baumung. 2011. Inbreeding depression on semen quality in Austrian dual-purpose Simmental bulls. Reprod. Domest. Anim. 46:e102-e104. https:// doi.org/10.1111/j.1439-0531.2010.01645.x.

Mc Parland, S., F. Kearney, and D. P. Berry. 2009. Purging of inbreeding depression within the Irish Holstein-Friesian population. Genet. Sel. Evol. 41:16. https://doi.org/10.1186/1297-9686-41-16.

McQuillan, R., A. L. Leutenegger, R. Abdel-Rahman, C. S. Franklin, M. Pericic, L. Barac-Lauc, N. Smolej-Narancic, B. Janicijevic, O. Polasek, A. Tenesa, A. K. MacLeod, S. M. Farrington, P. Rudan, C. Hayward, V. Vitart, I. Rudan, S. H. Wild, M. G. Dunlop, A. F. Wright, H. Campbell, and J. F. Wilson. 2008. Runs of homozygosity in European populations. Am. J. Hum. Genet. 83:359-372. https://doi.org/10.1016/j.ajhg.2008.08.007.

Meuwissen, T. H. E. 1997. Maximizing the response to selection with a predefined rate of inbreeding. J. Anim. Sci. 75:934-940. https:// doi.org/10.2527/1997.754934x.

Misztal, I., S. Tsuruta, T. Strabel, B. Auvray, T. Druet, and D. Lee. 2002. BLUPF90 and related programs (BGF90). Pages 7-28 in
Proc. 7th World Congress on Genetics Applied to Livestock Production, Montpellier, France, Aug. 19-23, 2002.

Peripolli, E., D. P. Munari, M. V. G. B. Silva, A. L. F. Lima, R. Irgang, and F. Baldi. 2017. Runs of homozygosity: Current knowledge and applications in livestock. Anim. Genet. 48:255-271. https://doi .org/10.1111/age.12526.

Pryce, J. E., M. Haile-Mariam, M. E. Goddard, and B. J. Hayes. 2014. Identification of genomic regions associated with inbreeding depression in Holstein and Jersey dairy cattle. Genet. Sel. Evol. 46:71. https://doi.org/10.1186/s12711-014-0071-7.

Rodríguez-Ramilo, S. T., J. M. Elsen, and A. Legarra. 2019. Inbreeding and effective population size in French dairy sheep: Comparison between genomic and pedigree estimates. J. Dairy Sci 102:4227-4237. https://doi.org/10.3168/jds.2018-15405.

Rodríguez-Ramilo, S. T., J. Fernández, M. A. Toro, D. Hernández, and B. Villanueva. 2015. Genome-wide estimates of coancestry, inbreeding and effective population size in the Spanish Holstein population. PLoS One 10:e0124157. https://doi.org/10.1371/ journal.pone.0124157.

Silió, L., M. C. Rodríguez, A. Fernández, C. Barragán, R. Benítez C. Óvilo, and A. I. Fernández. 2013. Measuring inbreeding and inbreeding depression on pig growth from pedigree or SNP-derived metrics. J. Anim. Breed. Genet. 130:349-360. https://doi.org/10 $.1111 /$ jbg. 12031 .

VanRaden, P. M. 1992. Accounting for inbreeding and crossbreeding in genetic evaluation of large populations. J. Dairy Sci. 75:3136-3144. https://doi.org/10.3168/jds.S0022-0302(92)78077-1.

VanRaden, P. M. 2008. Efficient methods to compute genomic predictions. J. Dairy Sci. 91:4414-4423. https://doi.org/10.3168/jds .2007-0980.

Varona, L., J. Altarriba, C. Moreno, M. Martínez-Castillero, and J. Casellas. 2019. A multivariate analysis with direct additive and inbreeding depression load effects. Genet. Sel. Evol. 51:78. https:/ /doi.org/10.1186/s12711-019-0521-3.

Zhang, Q., M. P. Calus, B. Guldbrandtsen, M. S. Lund, and G. Sahana. 2015. Estimation of inbreeding using pedigree, 50k SNP chip genotypes and full sequence data in three cattle breeds. BMC Genet. 16:88. https://doi.org/10.1186/s12863-015-0227-7.

\section{ORCIDS}

S. T. Rodríguez-Ramilo () https://orcid.org/0000-0001-7150-0692

I. Aguilar ๑ https://orcid.org/0000-0002-1038-4752

A. Legarra @ https://orcid.org/0000-0001-8893-7620

Z. G. Vitezica (ㄴ) https://orcid.org/0000-0002-3162-7258 